\title{
PERFORMANCE OF A V-TROUGH PHOTOVOLTAIC/THERMAL CONCENTRATOR
}

\author{
R. Künnemeyer *, T.N. Anderson ${ }^{+}$, M. Duke ${ }^{1 *}$ and J.K. Carson* \\ *School of Engineering, University of Waikato, Hamilton, New Zealand, 3240 \\ ${ }^{+}$School of Engineering, Auckland University of Technology, Auckland, New Zealand, 1142
}

\begin{abstract}
The idea of concentrating solar energy to increase the output of photovoltaic and solar thermal collectors is an area that has received significant attention. In this study, a design model for a V-trough concentrating photovoltaic/thermal solar collector was theoretically analysed and validated with experimental data.
\end{abstract}

The results showed that the V-trough offered improved electrical yields from both concentrating radiation onto the photovoltaic cells and also by actively cooling them. Also, it was shown that the Vtrough could be made of a durable (long life) stainless steel, rather than the more reflective aluminium, while still offering a $25 \%$ increase in incident radiation over a typical year. However it was noted that modifications would be needed to improve cooling and to increase the thermal efficiency by reducing heat losses.

\section{KEYWORDS:}

Concentrator; photovoltaic/thermal; V-trough

\section{INTRODUCTION}

In recent times there has been an increased interest in the development of Photovoltaic/Thermal (PVT) solar energy systems that generate both thermal and electrical energy (Van Helden et al. 2004, Tripanagnostopoulos et al., 2002, Huang et al., 2001). These studies have shown that PVT collectors

\footnotetext{
${ }^{1}$ Corresponding Author: Tel.: +64 78384522 Fax: +64 78384835

E-mail address: dukemd@waikato.ac.nz (M. Duke)
} 
can have high overall combined efficiencies and can be more cost effective than stand alone PV and solar thermal systems.

A significant number of the studies into PVT systems have produced "standalone" collectors similar to those already used for water heating (Garg and Agarwal, 1995, Chow et al., 2007, Dupeyrat, 2011). There are however shortcomings in existing PVT systems: in particular a comparatively high cost by virtue of the use of photovoltaics. A potential solution to this shortcoming is to develop PVT collectors which incorporate concentrators to increase the output from the photovoltaics using lower cost material.

Tripanagnostopoulos et al. (2002) discussed perhaps the simplest incarnation of a concentrating PVT concentrator. In their system they used a reflector plate to direct extra solar radiation onto a PVT collector giving a concentration ratio of approximately 1.3. They found that the use of this simple concentrator increased the thermal efficiency of their PVT collector from 38\% to approximately $60 \%$.

Similarly, concentration of solar radiation can also be achieved with compound parabolic concentrators (CPC), linear or circular Fresnel lenses or reflectors, or with parabolic dishes. Garg and Adhikari (1999) demonstrated the use of several truncated CPCs in a single PVT module. They found that their collector for air heating, with a concentration ratio of 3, resulted in better efficiencies when integrated into a system. A similar system was also demonstrated by Othman et al. (2005). However, where Garg and Adhikari used a single pass to heat air, they utilised a double pass with a rear finned surface in their system. The aim of the finned surface was to improve heat transfer on the rear face of the PV module.

As mentioned, concentration by linear Fresnel reflectors is also possible. Rosell et al. (2005) demonstrated a system based on this method that had a concentrating ratio of 11 . They were able to obtain a maximum thermal efficiency of approximately $60 \%$ from their system with no electrical load. 
Another variation on line focusing PVT collectors was the CHAPS (concentrating heat and power system) discussed by Coventry (2005), which used a parabolic trough reflector with a PVT module mounted at its focus. The system had a concentration ratio of 37 and had a maximum reported combined efficiency of $69 \%$. Coventry noted that although the system had a lower thermal efficiency than those reported in other studies, the heat losses from the CHAPS system where much lower, due to its smaller heated area. Coventry also noted that imperfections in the concentrator shape resulted in non-uniform illumination thus affecting the electrical performance.

Despite the work that has been undertaken, high concentration ratio CPCs and curved reflectors are challenging to manufacture accurately and are not necessarily need in many cases. A solution to this may be to develop simple V-trough style concentrators that lend themselves to easy fabrication. In this vein Chong et al (2012) and Kostic and Pavlovic (2012) demonstrated the use of V-trough solar concentrators for heating water and most recently, Riffat and Mayere (2013) suggested that V-troughs could be utilised in solar desalination systems. Such systems have been shown to provide an opportunity to improved output from photovoltaic and thermal systems. An early study by Bannerot and Howell (1979) had suggested that static V-trough collectors could achieve an annual average concentration ratio of over 1.2 for locations with a high diffuse solar fraction, and might be suited to applications where the reflectors were offsetting the cost of expensive solar absorbers such as photovoltaics.

Therefore in this study a concentrator system was developed that incorporated a V-trough concentrator to determine if such a system could produce a worthwhile increase in electrical and thermal energy for a water cooled PVT style collector.

\section{THEORETICAL ASSESSMENT OF A V-TROUGH CONCENTRATOR}


The solar concentrator proposed for this study had to be robust enough to last over 30 years while maintaining its mechanical integrity and not corroding. Previously Anderson et al. (2009) had demonstrated the use of PVT collectors based on trapezoidal profiled long run metal roofs where passageways were formed in the trough of the roof profile for the thermal cooling medium to travel through. Subsequently, a cover having polycrystalline PV cells laminated to its surface was bonded into the trough, thus forming a tube to which heat could be transferred. As such, it was proposed that this concept be extended by increasing the depth of the troughs, such that the inclined sides acted as reflective elements, the result being a photovoltaic thermal concentrator as shown in Figure 1. Additionally, to meet the design life it was suggested that the concentrator be constructed from mirror finished stainless steel sheet (Nostell et al., 1998) to cope with New Zealand's corrosive maritime climate.

In general, a flat plate solar collector mounted at an angle close to latitude will give the maximum annual output. Therefore it was decided that, when installed, the photovoltaic absorber in the V-trough should be inclined to the horizontal at an angle equal to the local latitude (37.5 degrees) with the troughs being oriented East-West. Additionally, it was suggested that the V-trough half angle $(\varphi)$ be set at 25 degrees, to account for the annual variation in declination, with the ratio of aperture area $(A)$ to trough area (a) being 2.36 (Figure 2).

\subsection{Optical Design of the V-trough Concentrator}

Before undertaking the fabrication of a collector, the performance of the concentrator was simulated using the analytical solution presented by Fraidenraich (1992 and 1998) for a V-trough concentrator. For the proposed design Fraidenraich's equations simplify substantially, as only one reflection off each sidewall needs to be considered, this ensures uniform illumination of the absorber and allows standard polycrystalline cells to be used (Freilich and Gordon, 1991). Therefore, the fraction of radiation incident on the aperture that reaches the absorber at the bottom of the trough without reflection $\left(P_{0}\right)$ is given by Equation 1 . 
$P_{0}=\left\{\begin{array}{rr}\frac{1}{C}+\frac{C-1}{2 C} \frac{\sin \left(-\left|\theta_{i}\right|+\varphi\right)}{\cos \theta_{i} \sin \varphi}, & \varphi<\left|\theta_{i}\right| \leq \alpha_{0} \\ \frac{1}{C}, & \left|\theta_{i}\right| \leq \varphi \\ 0, & \text { otherwise }\end{array}\right.$

Where: $\theta_{i}$ is the angle of the incident radiation with the trough normal (Figure 2), $C$ is the geometric concentration ratio $(A / a=2.36)$, and $\alpha_{0}$ is the maximum angle of acceptance, as given by Equation 2 .

$$
\alpha_{0}=\tan ^{-1}\left(\left[\frac{2}{C-1}+1\right] \frac{\sin \varphi}{\cos \varphi}\right)
$$

The fraction of reflected radiation that reaches the absorber from the right-hand wall $\left(P_{R}\right)$ can be given by Equation 3, and the radiation from the left-hand wall $\left(P_{L}\right)$ is given by Equation 4 .

$P_{R}=\left\{\begin{array}{rr}\frac{C-1 \frac{\sin \left(\theta_{i}+\varphi\right)}{2 C},}{\cos \theta_{i} \sin \varphi} & -\varphi \leq \theta_{i} \leq \alpha_{2} \\ \frac{\cos \left(\theta_{i}+2 \varphi\right)}{C \cos \theta_{i}}, & \alpha_{2}<\theta_{i} \leq \alpha_{0} \\ 0, & \text { otherwise }\end{array}\right.$

$P_{L}\left(\theta_{i}\right)=P_{R}\left(-\theta_{i}\right)$

Where $\alpha_{2}$ is the angular extent to which uniform illumination of the absorber occurs. For a concentrator undergoing a single reflection, this can be determined from Equation 5.

$$
\alpha_{2}=\tan ^{-1}\left(\frac{\frac{2}{C-1} \sin \varphi \cos 2 \varphi-\sin \varphi}{\frac{2}{C-1} \sin \varphi \sin 2 \varphi+\sin \cos \varphi}\right)
$$


In turn this leads to an expression for the optical efficiency $(\eta)$ of the concentrator (Fraidenraich, 1992 and 1998) as shown in Equation 6.

$\eta=P_{0}+\left(P_{R}+P_{L}\right) \rho$

Where the reflectance $(\rho)$ of the stainless steel was taken to be $=0.67$, (Karlsson and Ribbing, 1982). However, because this study was interested in the output of the V-trough relative to a plane inclined flat panel, it was necessary to consider the apparent concentration ratio of the absorber without the Vtrough reflectors.

In their study, Chong et al. (2012) showed that across the year the 'concentration ratio' of a flat absorber had an average value of between 0.88 and 0.98 . As such for this study, it was conservatively assumed that the relative concentration ratio was $90 \%$ of the maximum possible output enhancement of the V-trough for the entire year, as shown in Equation 7.

$$
C_{r e l}=0.9 \eta
$$




\subsection{Annual Solar Radiation Model}

To determine the performance of the V-trough concentrator at any particular instance within the year, the topocentric zenith and azimuth angles were determined from Reda and Andreas' (2008) solar position algorithm.

The local beam irradiance was estimated using Šúri and Hofierka’s (2004) method based on the Linke turbidity factor $\left(T_{L}\right)$. Diffuse radiation was assumed to be negligible. By combining the knowledge of concentrator' optical performance with the solar position and the estimated magnitude of the beam radiation it was possible to determine the irradiance occurring both on a flat inclined plane and on the absorber surface at any particular time, relative to an inclined flat plate.

As such, to validate the solar radiation model, consider a cool, dry, clear sky mid-winters day, where the Linke turbidity factor would be approximately 1.8 (Pedros et al., 1999). Under such conditions, the modelled irradiance on the V-trough absorber and a flat panel inclined at an angle equal to latitude can be compared to the radiation measured by a pyranometer as illustrated in Figure 3.

From Figure 3 it can be seen that there is good correspondence between the modelled and measured radiation data. In this instance it can be seen that the peak irradiance on the absorber is over $20 \%$ higher than the flat plate, however the overall energy yield is only $10 \%$ over the whole day. Moreover, there is a cross-over of the radiation incident on a flat plane with the radiation falling on the absorber surface. This cross-over illustrates that at times during the year the reflective sides of the V-trough shade the absorber surface. In the early morning the peak power output of the collector would be reduced but during the middle of the day the performance would be improved. To demonstrate this point further, in Figure 4 it can be seen that from sunrise to sunset near the equinoxes the concentration ratio of the $\mathrm{V}$-trough is greater than 1 , but for near the solstices there is a more gradual transition in the concentration ratio. This phenomenon is a function of the V-trough's geometry as well the absorber being mounted at an angle equal to latitude. 


\subsection{Thermal Modelling of the V-trough Concentrator}

To determine the thermal performance of the concentrator a one-dimensional steady state thermal model for an unglazed solar collector was utilised. Figure 5 shows a schematic representation of the heat balance used in this study, where under open circuit electrical conditions the useful heat gain can be calculated from Equation 8 (Duffie and Beckman, 2006).

$Q_{t}=A F_{R}\left[(\tau \alpha) \cdot G "-U_{L}\left(T_{i}-T_{a}\right)\right]$

Where the useful heat gain $\left(Q_{t}\right)$ can be represented as a function of the collector area $(A)$, the heat removal efficiency factor $\left(F_{R}\right)$, the transmittance-absorptance product of the collector $(\tau \alpha)$, the incident radiation ( $G$ ", which is taken as the product of the relative concentration ratio $\left(C_{r e l}\right)$ and the radiation on a flat inclined surface), the collector heat loss coefficient $\left(U_{L}\right)$ and the temperature difference between the collector inlet temperature $\left(T_{i}\right)$ and the ambient temperature $\left(T_{a}\right)$

Of these parameters, the transmittance-absorptance product is the only one that is based solely on a physical property of the collector material. The absorptance provides a measure of the proportion of the incoming solar radiation captured by the absorber surface, in this case the polycrystalline photovoltaic cells. The transmittance component measures the portion of the radiation transmitted by any glazing layer and in this case for an unglazed collector it was assumed to be equal to unity. Therefore, to understand the optical characteristics of the photovoltaic absorber it was decided to determine its absorptance characteristics over the Air Mass 1.5 (AM1.5) solar spectrum.

To determine the absorption of the photovoltaic absorber, the diffuse reflectance $(\rho)$ of a small sample was measured at $20 \mathrm{~nm}$ wavelength intervals between $300 \mathrm{~nm}$ and $2500 \mathrm{~nm}$, using a spectrophotometer and a $6^{\circ}$ integrating sphere at Industrial Research Limited (Wellington, NZ) under open circuit 
conditions. Based on the reflectance measurement results shown in Figure 6, it was possible to determine the absorptance $(\alpha)$ component from Equation 9, as the absorber was an opaque surface with zero transmittance.

$\alpha=1-\rho$

By integrating the absorptance derived from the measurements of the reflectance over the range of AM1.5 wavelengths it was found that the photovoltaic absorber had an absorptance value of 0.875 .

The heat removal efficiency factor $\left(F_{R}\right)$ can be derived from Equation 10, which accounts for the mass flow rate in the collector $(\dot{m})$ and the specific heat of the collector fluid $\left(C_{p}\right)$.

$$
F_{R}=\frac{\dot{m} C_{P}}{A U_{L}}\left[1-e^{-\frac{A U_{L} F^{\prime}}{m C_{P}}}\right]
$$

To determine the heat removal efficiency factor it is necessary to calculate a value for the corrected fin efficiency $\left(F^{\prime}\right)$. This is done by first calculating the fin efficiency $(F)$ using Equation 11 . This determines the efficiency of the finned area between the tube and reflector. To achieve this it takes into account the width of the photovoltaic absorber $(W)$ and the cooling channel width $(d)$. Furthermore, the coefficient $(M)$ accounts for the thermal conductivity and thickness of the photovoltaic absorber and is derived from Equation 12.

$F=\frac{\tanh \left(M \frac{W-d}{2}\right)}{\left(M \frac{W-d}{2}\right)}$

$$
M=\sqrt{\frac{U_{\text {loss }}}{k_{a b s} L_{a b s}+k_{P V} L_{P V}}}
$$


Therefore, the corrected fin efficiency ( $\left.F^{\prime}\right)$ can be calculated using Equation 13, the overall heat loss coefficient $\left(U_{L}\right)$ of the collector is the summation of the collector's edge (negligible), bottom and top losses. Further, $h_{P V A}$ is a "quasi" heat transfer coefficient to account for the bond resistance between the PV cell and the absorber (Zondag et al., 2002) and $h_{\text {fluid }}$ is the forced convection heat transfer coefficient inside the cooling passage determined from the Dittus-Boelter equation.

$$
F^{\prime}=\frac{\frac{1}{U_{L}}}{W\left[\frac{1}{U_{L}(d+(W-d) F)}+\frac{1}{W h_{P V A}}+\frac{1}{\pi d h_{\text {fluid }}}\right]}
$$

For an unglazed V-trough collector, the top loss coefficient is a function of both radiation and wind. As such it is necessary to calculate the top loss coefficient $\left(U_{\text {top }}\right)$ by taking the summation of the individual contributions of radiation, natural and forced convection. Under such conditions, the heat loss due to radiation can conservatively be expressed as a radiation heat transfer coefficient in terms of the sky temperature $\left(T_{s}\right)$, the mean collector plate temperature $\left(T_{p m}\right)$ the plate emissivity $\left(\varepsilon_{p}\right)$, and the Stefan-Boltzman constant $(\sigma)$ as shown in Equation 14.

$$
h_{r}=\sigma \varepsilon_{p}\left(T_{p m}^{2}+T_{s}^{2}\right)\left(T_{p m}+T_{s}\right)
$$

where the sky temperature is represented by a function of the ambient temperature as shown in Equation 15 (Fuentes, 1987).

$$
T_{s}=0.037536 T_{a}^{1.5}+0.32 T_{a}
$$

and the mean plate temperature is determined from Equation 16. 
$T_{p m}=T_{i}+\frac{Q_{t} / A}{F_{R} U_{L}}\left(1-F_{R}\right)$

Furthermore, the losses due to natural and forced convection must also be taken into account. Now although much work has been undertaken on the optical characteristics of V-troughs, there is a lack of relationships to describe the heat loss from these collectors. Therefore it is assumed that the forced convection heat transfer coefficient $\left(h_{w}\right)$ could be calculated using a correlation for flat plate absorbers in terms of wind velocity (v), as shown in Equation 17 (Watmuff et al., 1977), while the natural convection loss $\left(h_{n a t}\right)$ is represented by a function of the temperature difference between the mean collector plate temperature $\left(T_{p m}\right)$ and the ambient temperature $\left(T_{a}\right)$ as shown in Equation 18 (Eicker, 2003).

$h_{w}=2.8+3.0 v$

$h_{\text {nat }}=1.78\left(T_{p m}-T_{a}\right)^{1 / 3}$

Using this method it is possible to determine an overall convection heat transfer coefficient $\left(h_{c}\right)$ by combining both forced and natural convection heat transfer as shown in Equation 19.

$h_{c}=\sqrt[3]{h_{w}^{3}+h_{n a t}^{3}}$

Subsequently by taking the summation of the convection and radiation losses, it is possible to determine the overall top loss heat transfer coefficient $\left(U_{t o p}\right)$ for the unglazed collector.

Now, for an unglazed concentrator with no back insulation, it can be assumed that radiation losses between the back surface and the ground are negligible (due to the relatively low emissivity of the stainless steel and also the small temperature differences between the collector and the ground). 
However, both natural convection and wind losses are significant, and as such, the back loss $\left(U_{\text {back }}\right)$ can also be represented by Equation 19 (Eicker, 2003). Therefore the overall heat loss coefficient $\left(U_{L}\right)$ for the collector can be determined by taking the sum of the top ( $\left.U_{\text {top }}\right)$ and back $\left(U_{\text {back }}\right)$ losses.

Therefore, combining the modelled value of the concentration ratio with the prediction of solar radiation over the year, and the thermal modelling, it is possible to calculate the heat removed from the solar collector for any time on any day in the year, and thus its temperature.

On the basis of being able to determine the temperature of the concentrator, the electrical efficiency can be calculated based on the difference between the mean temperature and the Nominal Operating Cell Temperature (NOCT), which is typically taken as 298K. As such an increase in the mean temperature of the concentrator would result in a reduction in the power output.

For this study it was assumed that the modules had an efficiency of $14.5 \%$ at NOCT (being within the typical range of 10 to $20 \%$ ), and that the temperature dependent efficiency could be represented by Equation 20 (Skoplaki and Palyvos, 2009).

$\eta_{e}=0.145\left[1-0.045\left(T_{p m}-N O C T\right)\right]$

Therefore, the electrical output can be given by Equation 21 .

$Q_{e}=\eta_{e} A G^{\prime \prime}$

Finally by taking the ratio of the energy gain to the total radiation falling on the absorber area (Q/AG”) we can subsequently determine the overall theoretical efficiency of the collector. 


\section{CONCENTRATOR DESIGN AND EXPERIMENTAL SETUP}

In order for the outcomes of the theoretical assessment to be satisfactorily proven, it was necessary to validate the model against experimental data. To achieve this validation, it was decided to fabricate a prototype concentrator and examine its performance using a quasi-steady state outdoor thermal test. As previously discussed the collector was fabricated from a mirror finish stainless steel with the aim of providing a long lasting, reflective surface that is also suitable for fluid flow. Therefore a stainless steel sheet was folded to form a V-trough profile with a fluid channel in the centre. Custom manufactured photovoltaic modules were bonded into the trough creating a closed channel for fluid flow as previously shown in Figure 1. The photovoltaic modules comprised 14 standard polycrystalline cells $\left(156 \mathrm{~mm} \times 156 \mathrm{~mm}, I_{s c} \sim 8 \mathrm{~A}, V_{o c} \sim 0.6 \mathrm{~V}, \mathrm{FF} \sim 0.72\right.$, Efficiency $\left.\sim 14.5 \%\right)$ connected in series laminated onto a 1mm stainless steel sheet using EVA with a Tedlar top sheet with a rated output of 49Wp.

The fluid within the channel has two purposes; firstly to reduce the temperature of the photovoltaic cells (as it is well known that cooling mono-crystalline and polycrystalline silicon PV cells results in increased electrical power output) and secondly to produce thermal energy (which would be suitable for use with a heat pump). Four concentrator modules were mounted on a frame and cooling fluid was pumped through the panels (Figure 7). Furthermore a flat PV module of the same rated power with no cooling and no concentration was mounted adjacent to the concentrator modules to act as a reference collector.

To evaluate the concentrator performance T-type thermocouples were used to measure the inlet $\left(T_{\text {in }}\right)$ and outlet $\left(T_{\text {out }}\right)$ temperatures of the panels as well as their surface temperatures. The volumetric flow rate $(V)$ of water through the collector was measured using a paddle wheel flow sensor and the incident solar radiation $(G)$ was measured using a pyranometer mounted parallel to the panels as shown in Figure 8. 
To determine the electrical output of the modules, the data acquisition system switched between measuring the open circuit voltage $\left(V_{o c}\right)$ across the panel and the short circuit current $\left(I_{s c}\right)$ of each panel at 15-second intervals. From this it was possible to determine the output power of the collectors from Equation 22.

$P=F F V_{o c} I_{s c}$

where $I_{s c}$ is the measured short circuit current, $V_{o c}$ is the measured open circuit voltage and $F F$ is the fill factor given by the PV cell manufacturer to be 0.72 , and which is assumed to be constant.

\section{RESULTS}

Having developed a mathematical description of the concentration ratio, it was decided to test this against the experimental output from a clear winter's day. For the test day, the optical model suggested that the concentration ratio of the collector would vary, as shown in Figure 9. From Figure 9 it can be seen that the model suggests that the geometry of the V-trough will result in shading of the absorber, in the early morning and afternoon. This is manifested as a concentration ratio of less than one, i.e. the radiation at the absorber would be less than if the collector was a flat plate. However, during the middle of the day, there is a higher ratio. Furthermore, it can be seen that there is good correspondence between the optical model and the experimentally derived value of the relative concentration ratio, taken as the ratio of the output from a concentrated collector to that of the reference module.

Now, polished stainless steel with a reflectivity of 0.67 was used to fabricate the concentrator. However in order to improve the yield from the collector, it is possible that aluminium could be used. The use of aluminium would result in an increase in the reflectivity to a value of 0.9 (Fend et al., 2003) which should in turn lead to higher irradiance at the absorber surface. In Figure 10 it can be seen that aluminium would increase the peak irradiance on the absorber, compared to a stainless steel 
reflector, by approximately $10 \%$. However this gain may be at the cost of longevity (Nostell et al, 1998), particularly in a maritime climate.

Having ascertained that the model was able to determine the relative concentration ratio, it was decided to determine if the electrical output power could also be predicted by the theoretical model. In Figure 11 it can be seen that it was possible to estimate of the power output from a flat photovoltaic module and a concentrator module both nominally rated at $49 \mathrm{Wp}$. Thus, having validated the models ability to predict the electrical output, it was decided to examine how the cooling system affected the electrical output. In considering the concentrator one of the shortcomings of not cooling the concentrator is that it results in a reduced power output from the photovoltaic cells as illustrated in Figure 12. As an aside, in considering a glazed concentrator without cooling, the reduction in power would be even more dramatic than the $2 \%$ reduction in peak power observed here.

For the concentrator, the decrease in power output is manifested principally in the form of a reduced voltage output from the collector, due to the change in temperature. In Figure 13, it can be seen that there is a noticeable difference in output voltage between the cooled and uncooled modules due to the temperature of the modules varying over the course of the day.

Having validated the electrical output from the model it was decided to examine its ability to predict the thermal performance. In Figure 14, it can be seen that there is a slight divergence between the modelled and theoretical thermal output that may be attributable to the calculation of the sky temperature influencing the radiation heat loss and the convective heat loss varying from the correlation used in the model. Similarly, in Figure 15, the prediction of the overall power output (thermal plus electrical) from the collector is also influenced by the variation in the temperature prediction. However, when considering the overall efficiency of the collector, it can be seen in Figure 16 that the model provides a relatively good prediction of the concentrator performance. 
In Figure 16 it can be seen that the peak combined thermal and electrical efficiency of the collector is in the order of $35 \%$. As such, it could be argued that the concentrator performs poorly when compared to purpose designed solar collectors with peak efficiencies in excess of $70 \%$. However, this lower efficiency is due to the increased heat losses by radiation and convection in the absence of a glazing layer (Anderson et al., 2009) that reduce the thermal efficiency.

One of principal advantages of the concentrator is that it provides not only an improved electrical output, but also the thermal output that could be used in conjunction with a heat pump. In achieving this, the absorber is in effect improving the energy output compared to standard photovoltaic panels; similarly a solar thermal collector does not provide electrical energy. As such it is important to emphasise the total power output for the cooled concentrator module as shown in Figure 15, and how this would compare to the system if it were just a photovoltaic concentrator. Here it can be seen the combined efficiency of the concentrator module is over $30 \%$, whereas photovoltaic modules typically have efficiencies in the order of $15 \%$. Hence a concentrator offers a significant benefit in terms of utilising an increased fraction of the incoming solar energy.

Now it was previously noted that at times during a day, self-shading of the concentrator could occur and this leads to reduced output. Though shading of photovoltaic cells is generally undesirable at any time it could be argued that in a climate such as Australia's, that this corresponds to times of low radiation and electrical demand, whereas the output is markedly increased around solar noon when electrical demand is high due to an increased demand for air-conditioning (Watt et al., 2003).

More tellingly, if we examine the now validated model output from the concentrator and explore the variation in concentration ratio (for each months median day) over the year based on the monthly average Linke turbidity index' (Figure 17), we see that the addition of the V-Trough results should lead to a $25 \%$ increase in the relative concentration ratio across the year, similar to that predicted by Bannerot and Howell (1979). 
This result suggests that despite the small performance increases observed in the experiments (mid winter) the output from the collector will be significantly increased around the equinoxes with a resultant increase in the annual output.

\section{CONCLUSION}

Based on the results presented, it can be seen that the concept of a photovoltaic thermal concentrator is feasible and has the potential to offer significant efficiency improvements over existing photovoltaic modules. Though it could be argued that photovoltaic systems are reducing in price, they are still relatively expensive, and the use of low cost reflective elements offers the opportunity to improve electrical energy yields using low cost materials.

Moreover, the cooling of the cells in addition to improving the electrical output offers a thermal energy source. The efficiency of energy capture for the total area is markedly improved. However, it should also be noted that in order to achieve further improvements from the concentrator there is a need to closer examine the system and look at means of reducing convective and radiative heat losses.

\section{ACKNOWLEDGEMENTS}

The authors would like to thank Mr Josh Garrett for his assistance in undertaking some of the experimental work as part of his summer research project and funded by the University of Waikato.

\section{REFERENCES}

Anderson, T. N., Duke, M., Morrison, G. L. \& Carson, J. K. (2009), Performance of a building integrated photovoltaic/thermal (BIPVT) solar collector, Solar Energy, 83, 445 - 455 
Bannerot, R.B. \& Howell, J.R., (1979), Predicted daily and yearly average radiative performance of optimal trapezoidal groove solar energy collectors, Solar Energy, 22 (3), 229-234

Chong, K.K., Chay, K.G., Chin K.H., (2012), Study of a solar water heater using stationary V-trough collector, Renewable Energy, 39 (1), 207-215

Chow, T.T., He, W., Ji, J., (2007), An experimental study of façade-integrated photovoltaic/waterheating system, Applied Thermal Engineering, 27 (1), 37-45

Coventry, J. S. (2005), Performance of a concentrating photovoltaic/thermal solar collector, Solar Energy, 78, $211-222$

Duffie, J.A., \& Beckman, W.A., (2006), Solar Engineering of Thermal Processes, Wiley, New York

Dupeyrat, P., Ménézo, C., Rommel, Henning, M.H., (2011), Efficient single glazed flat plate photovoltaic-thermal hybrid collector for domestic hot water system, Solar Energy, 85 (7), 1457-1468

Eicker, U., (2003), Solar technologies for buildings, John Wiley and Sons, Chichester

Fend, T., Hoffschmidt, B., Jorgensen, G., Küster, H., Krüger, D., Pitz-Paal, R., Rietbrock, P., \& Riffelmann, K.-J., (2003), Comparative assessment of solar concentrator materials, Solar Energy, 74, 149-155

Fraidenraich, N., (1992), Analytic solutions for the optical properties of V-trough concentrators, Applied Optics, 31 (1), 131 - 139 
Fraidenraich, N., (1998), Design procedure of V-trough cavities for photovoltaic systems, Progress in Photovoltaics: Research and Applications, 6 (1), 43-54

Freilich, J. \& Gordon, J.M., (1991), Case study of a central-station grid-intertie photovoltaic system with V-trough concentration, Solar Energy, 46 (5), 267-273

Fuentes, M.K., (1987), A simplified thermal model for flat-plate photovoltaic arrays, Sandia National Laboratories Report, SAND85-0330-UC-63, Albuquerque

Garg, H.P. \& Adhikari, R.S., (1999), Performance analysis of a hybrid photovoltaic/thermal (PV/T) collector with integrated CPC troughs, International Journal of Energy Research, 23, (15), 1295-1304

Garg, H.P. \& Agarwal, R.K., (1995), Some aspects of a PV/T collector/forced circulation flat plate solar water heater with solar cells, Energy Conversion and Management, 36 (2), 87-99

Huang, B. J., Lin, T. H., Hung, W. C., \& Sun, F. S., (2001) Performance evaluation of solar photovoltaic/thermal systems, Solar Energy, 70 (5), 443-448

Karlsson, B. \& Ribbing, C. G., (1982), Optical constants and spectral selectivity of stainless steel and its oxides, Journal of Applied Physics, 53 (9), 6340-6346

Kostić, L.T. \& Pavlović, Z.T., (2012), Optimal position of flat plate reflectors of solar thermal collector, Energy and Buildings, 45, 161-168

Nostell, P., Roos, A., \& Karlsson, B., (1998), Ageing of solar booster reflector materials, Solar Energy Materials and Solar Cells, 54, 235-246 
Othman, M.Y.H., Yatim, B., Sopian, K., \& Bakar, M.N.A., (2005), Performance analysis of a doublepass photovoltaic/thermal (PV/T) solar collector with CPC and fins, Renewable Energy, 30 (13), 2005-2017

Pedrós, R., Utrillas, M. P., Martínez-Lozano, J. A., \& Tena, F., (1999), Values of broad band turbidity coefficients in a Mediterranean coastal site, Solar Energy, 66 (1), 11-20

Reda, I. \& Andreas, A. (2008), Solar position algorithm for solar radiation applications, Technical report WU1D5600, National Technical Information Service, U.S. Department of Commerce

Riffat, S., \& Mayere, A., (2013), Performance evaluation of v-trough solar concentrator for water desalination applications, Applied Thermal Engineering, 50 (1), 234-244

Rosell, J.I., Vallverdu, X., Lechon, M.A \& Ibanez, M, (2005), Design and simulation of a low concentrating photovoltaic/thermal system, Energy Conversion and Management, 46 (18-19), 30343046

Skoplaki, E., \& Palyvos, J.A., (2009), On the temperature dependence of photovoltaic module electrical performance: A review of efficiency/power correlations, Solar Energy, 83, 614-624

Sûri, M. \& Hofierka, J. (2004), A new GIS-based solar radiation model and its application to photovoltaic assessments, Transactions in GIS, 8 (2), 175-190

Tripanagnostopoulos, Y., Nousia, T., Souliotis, M. \& Yianoulis, P. (2002), Hybrid photovoltaic/thermal solar systems, Solar Energy, 72 (3), 217-234 
van Helden, W. G. J., Van Zolingen, R. J. C. \& Zondag, H. A. (2004), PV thermal systems: PV panels supplying renewable electricity and heat, Progress in Photovoltaics: Research and Applications, 12, $415-442$

Watmuff, J.H., Charters, W.W.S., \& Proctor, D, (1977), Solar and wind induced external coefficients for solar collectors, Comples No. 2, 56

Watt, M., Outhred, H.R., Oliphant, M. \& Collins, R., (2003), Using PV to Meet Peak Summer Electricity Loads, Proceedings of ANZSES Annual Conference, Destination Renewables, Melbourne, December 2003, 486-495

Zondag, H.A., de Vries, D.W., van Helden, W.G.J., van Zolingen, R.J.C., \& van Steenhoven, A.A., (2002 ), The thermal and electrical yield of a PV-thermal collector, Solar Energy, 72, (2), 113-128 


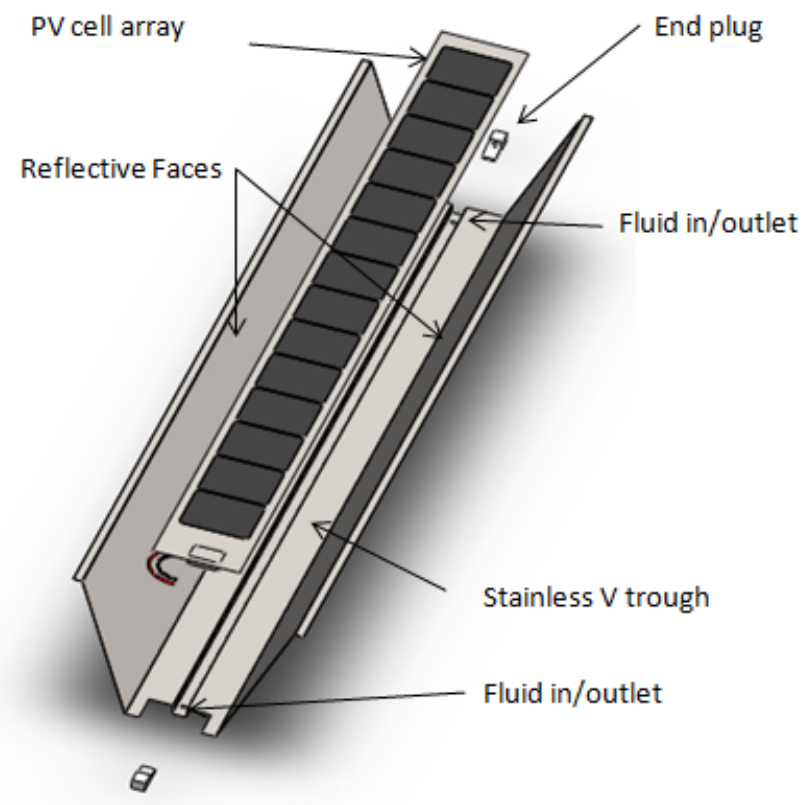

Figure 1: V-trough concentrator 


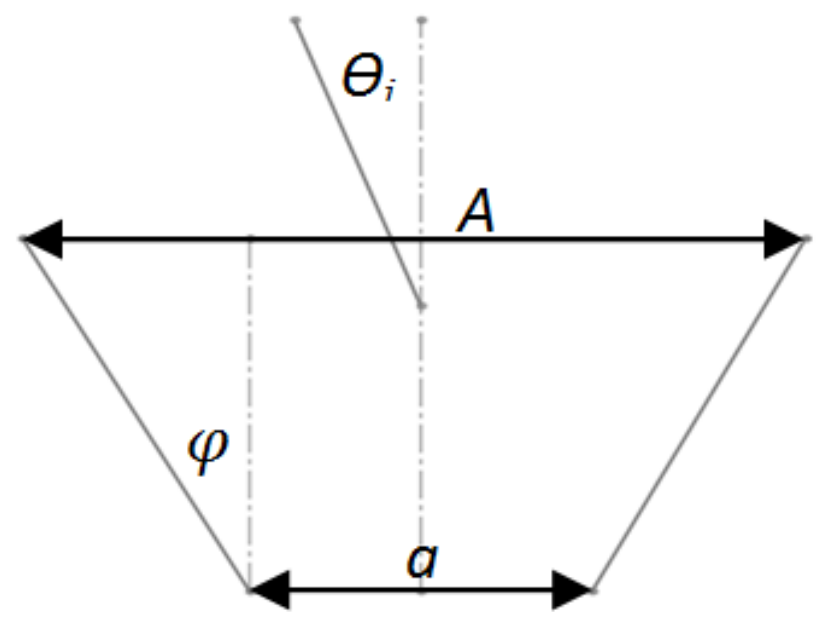

Figure 2: V-trough cross-section 


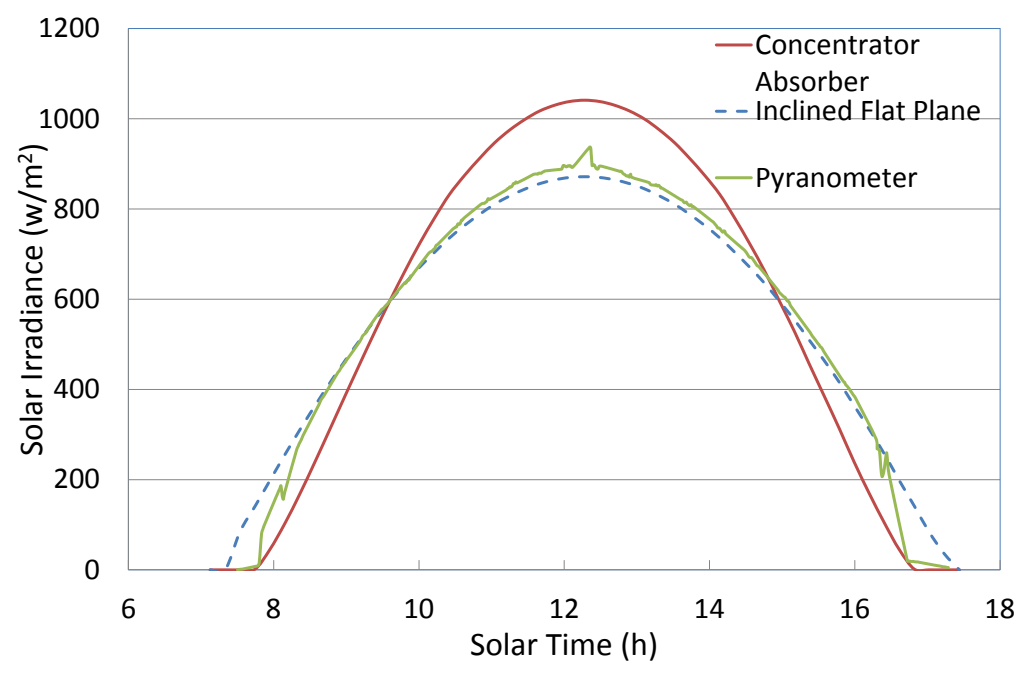

Figure 3: Predicted incident radiation on flat and concentrator absorbers 


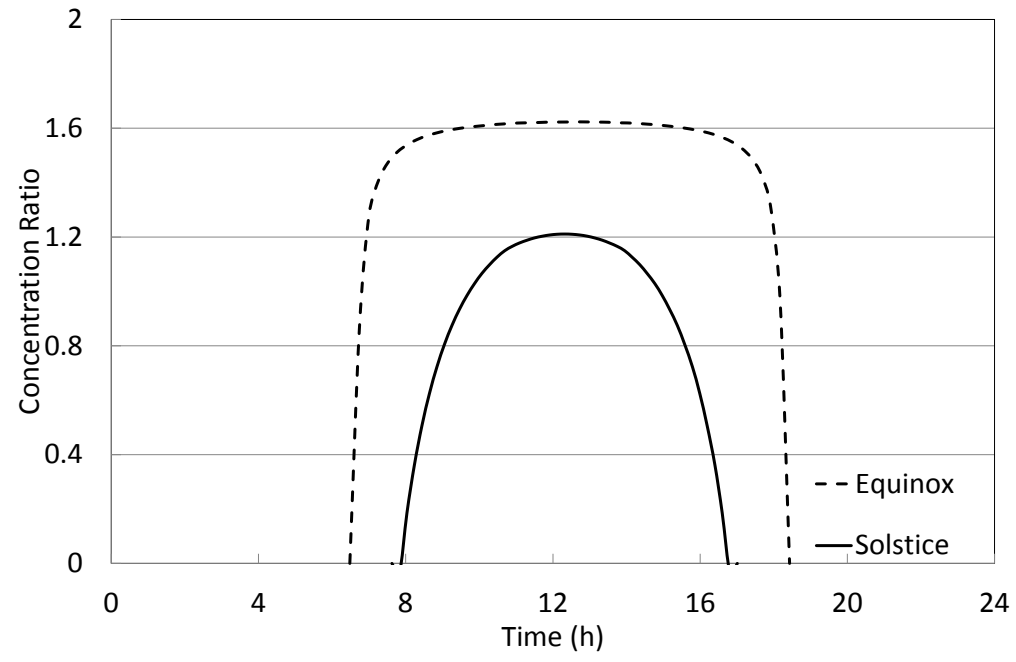

Figure 4: V-trough concentration ratio near an equinox and a solstice 


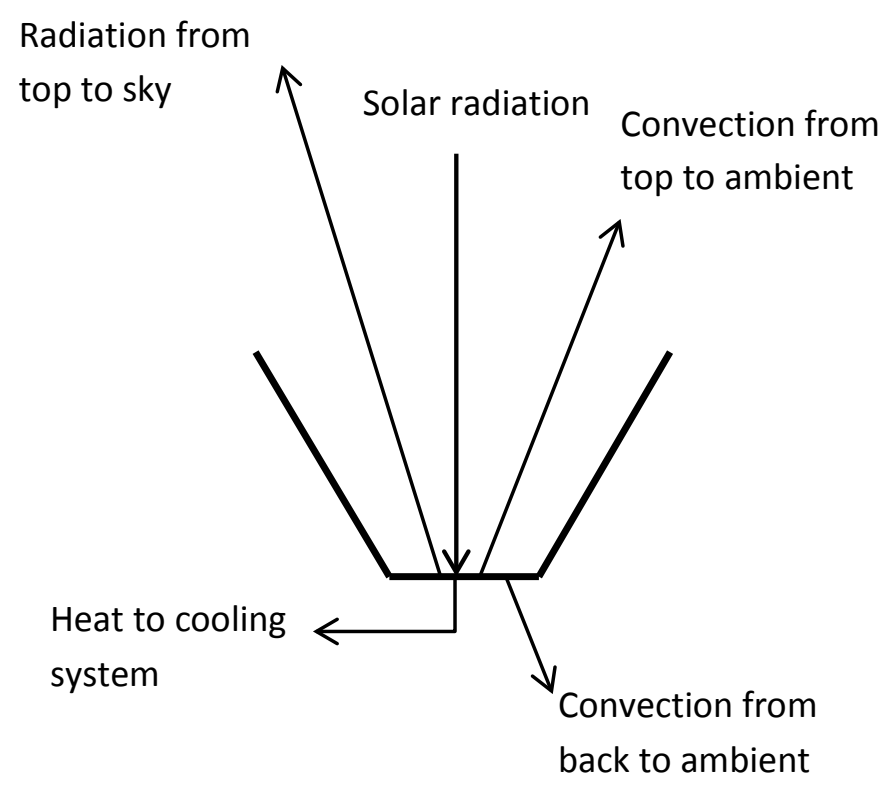

Figure 5: Schematic representation of V-trough heat balance 


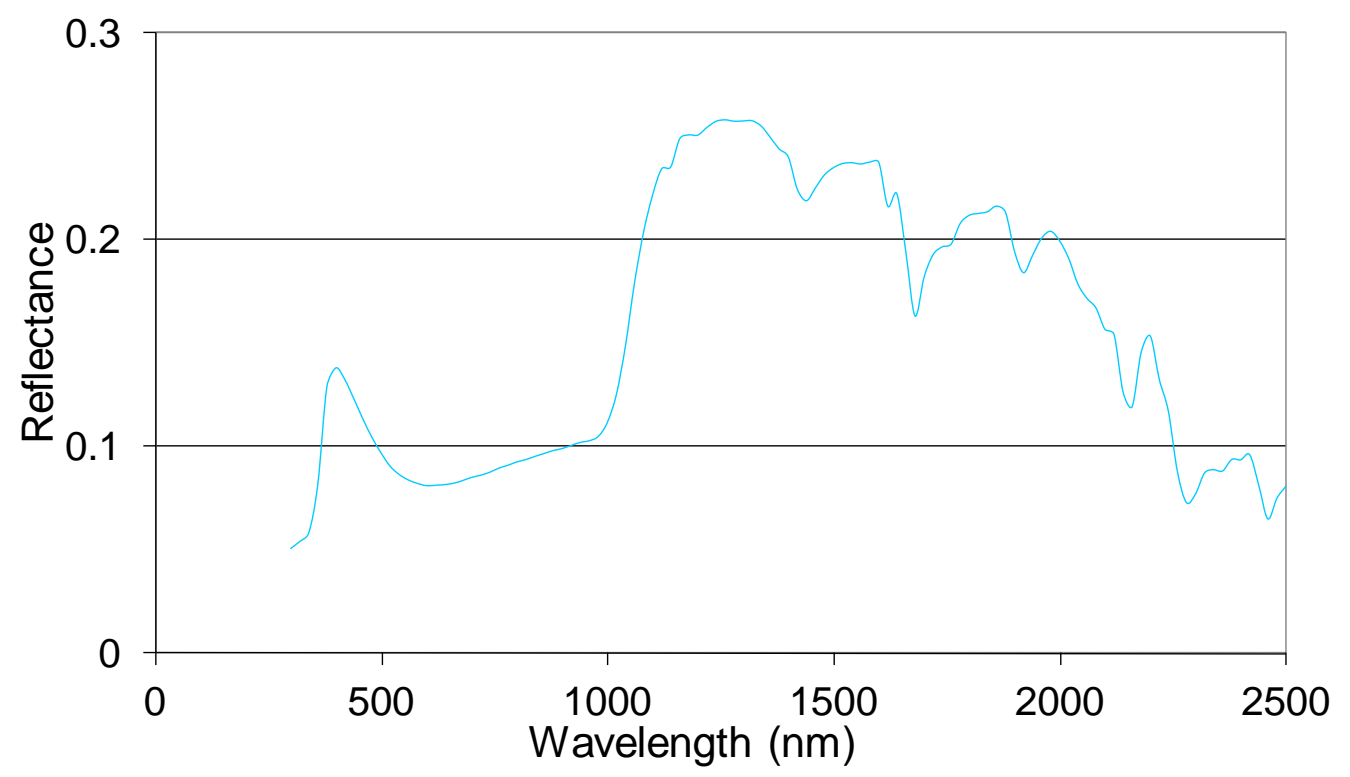

Figure 6: Reflectance from photovoltaic absorber sample over AM1.5 spectrum 


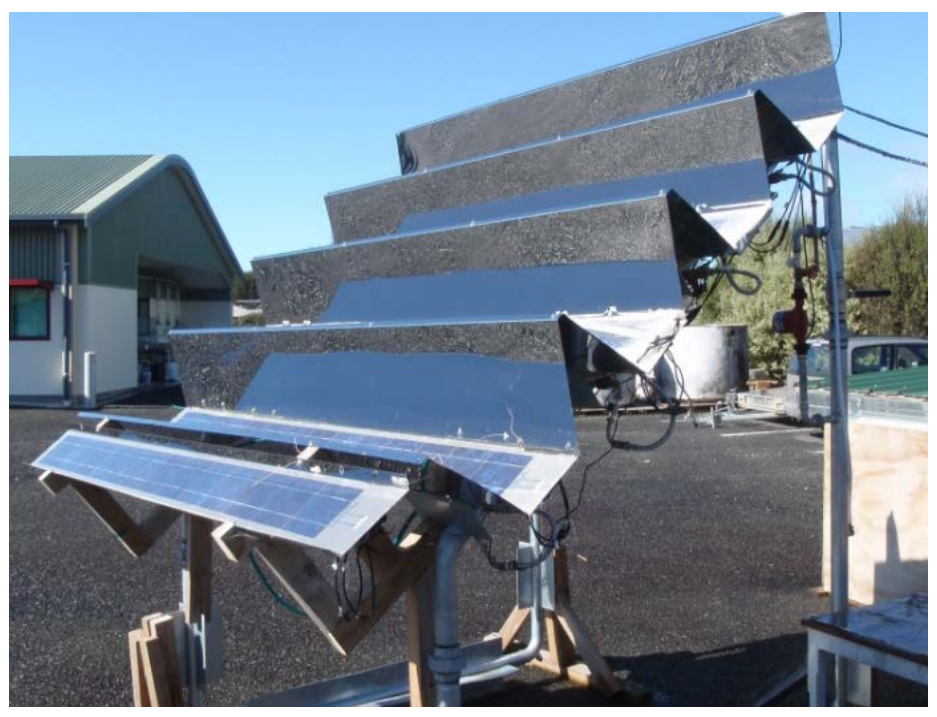

Figure 7: Experimental concentrator apparatus 


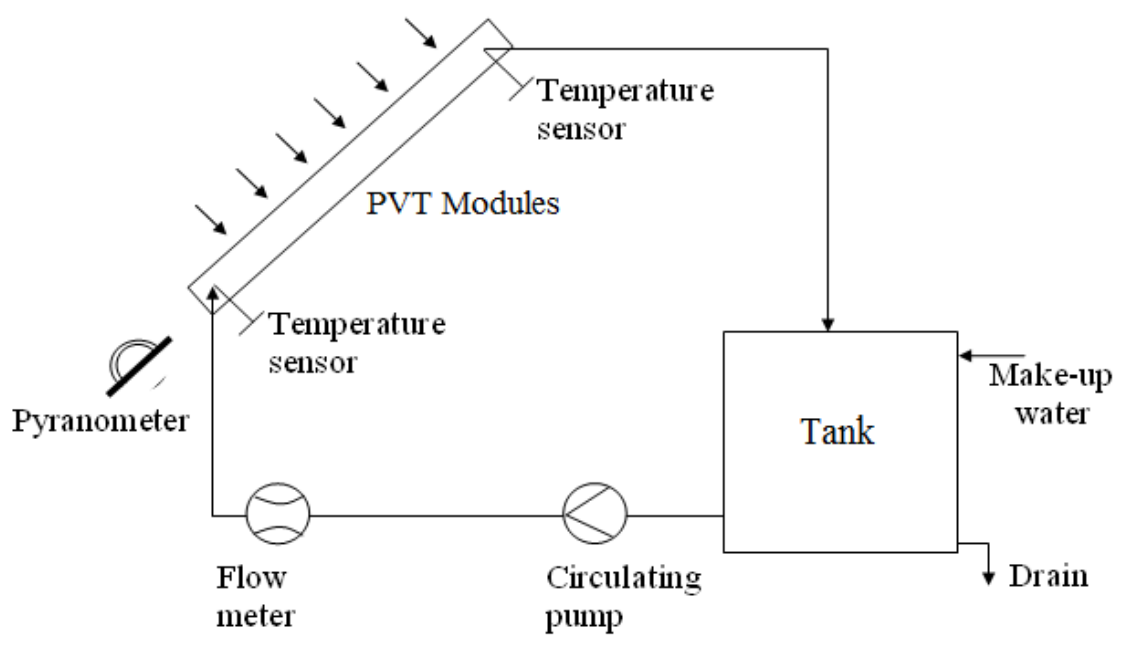

Figure 8: Schematic diagram of testing system 


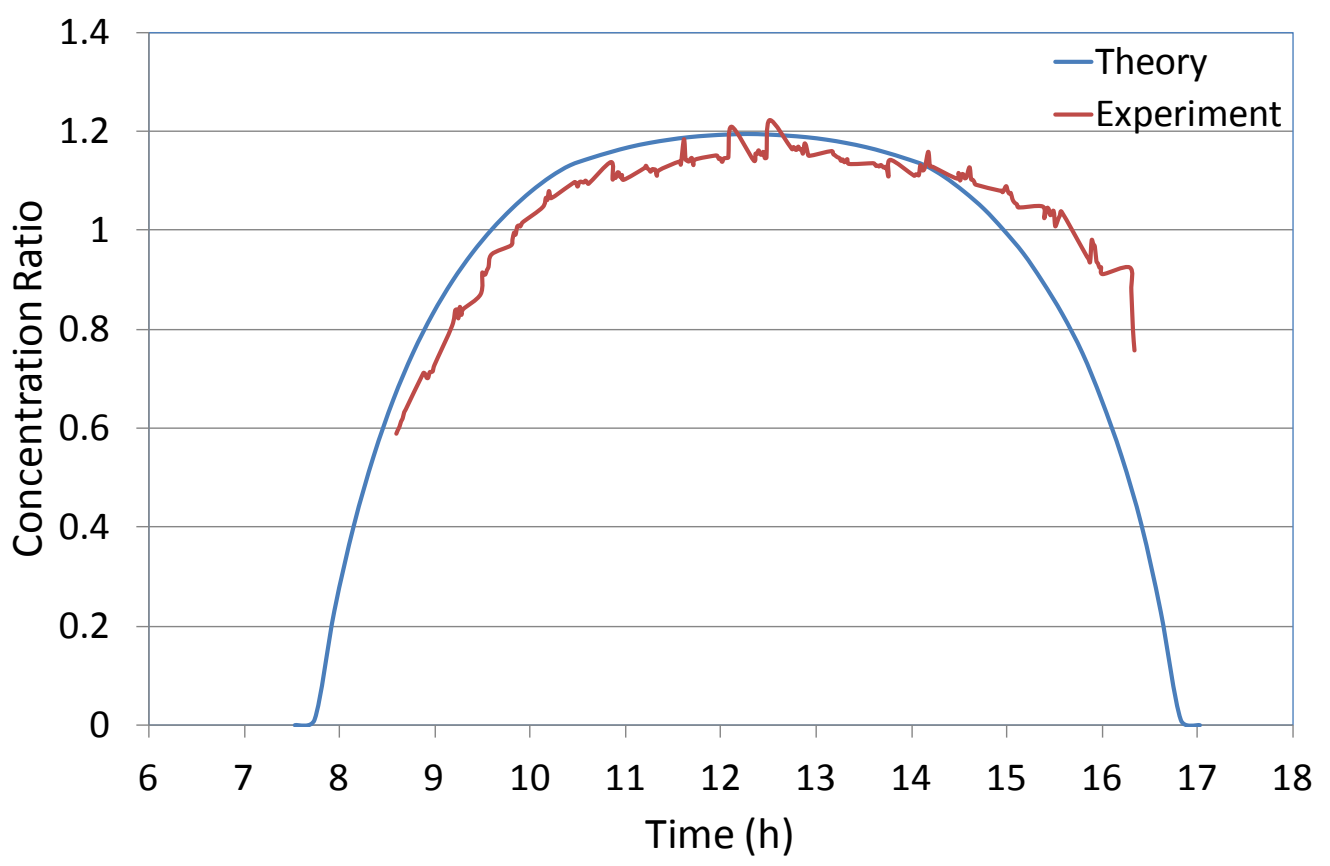

Figure 9: Modelled and measured relative concentration ratio 


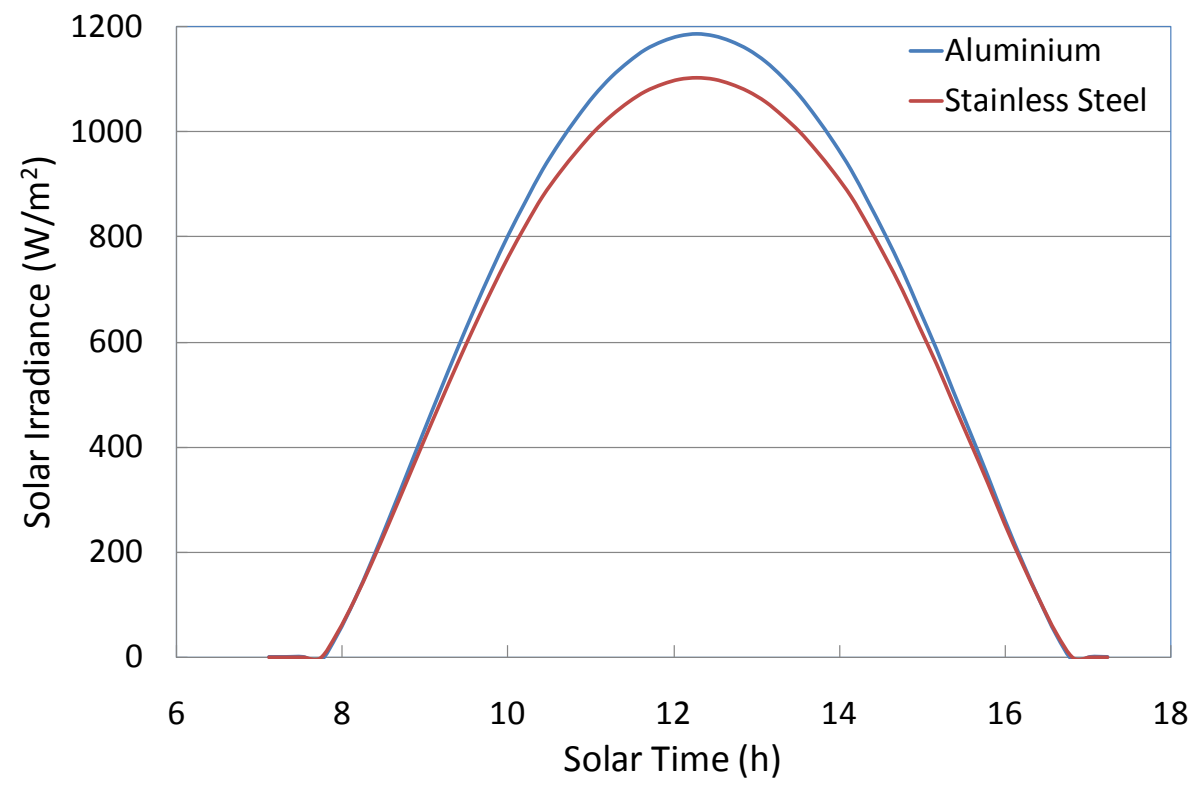

Figure 10: Absorber irradiance for aluminium and stainless steel concentrators 


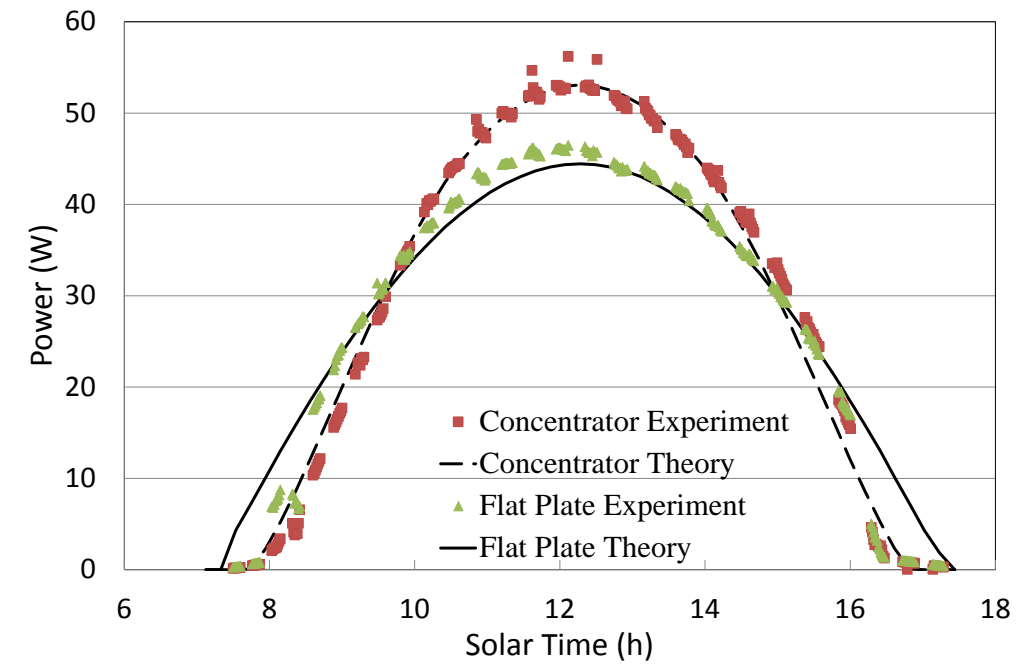

Figure 11: Experimental and theoretical electrical output of concentrator and reference module 


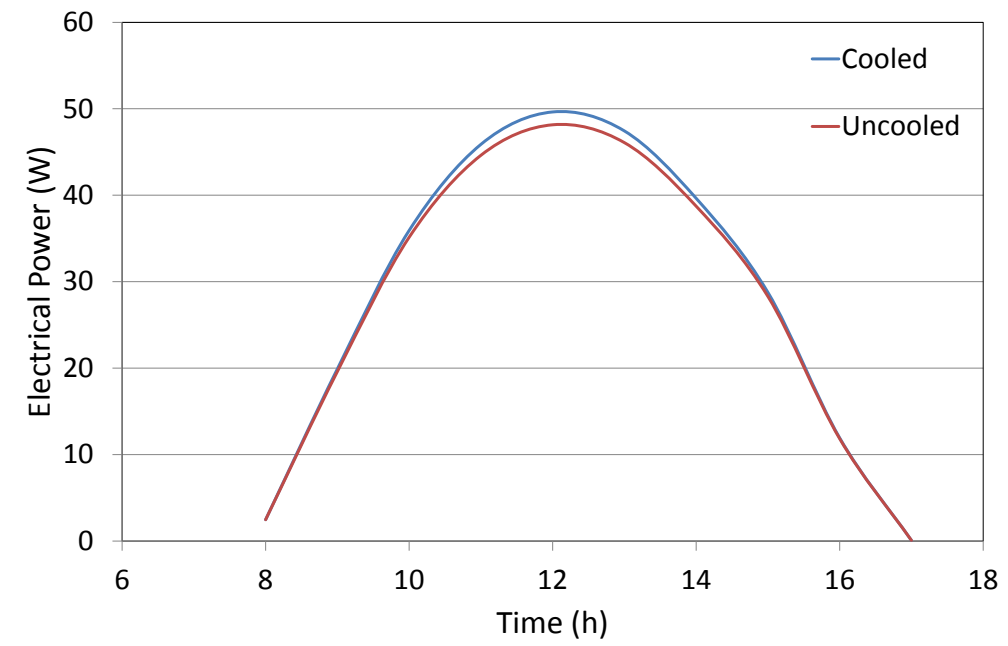

Figure 12: Electrical output from cooled and un-cooled concentrator 


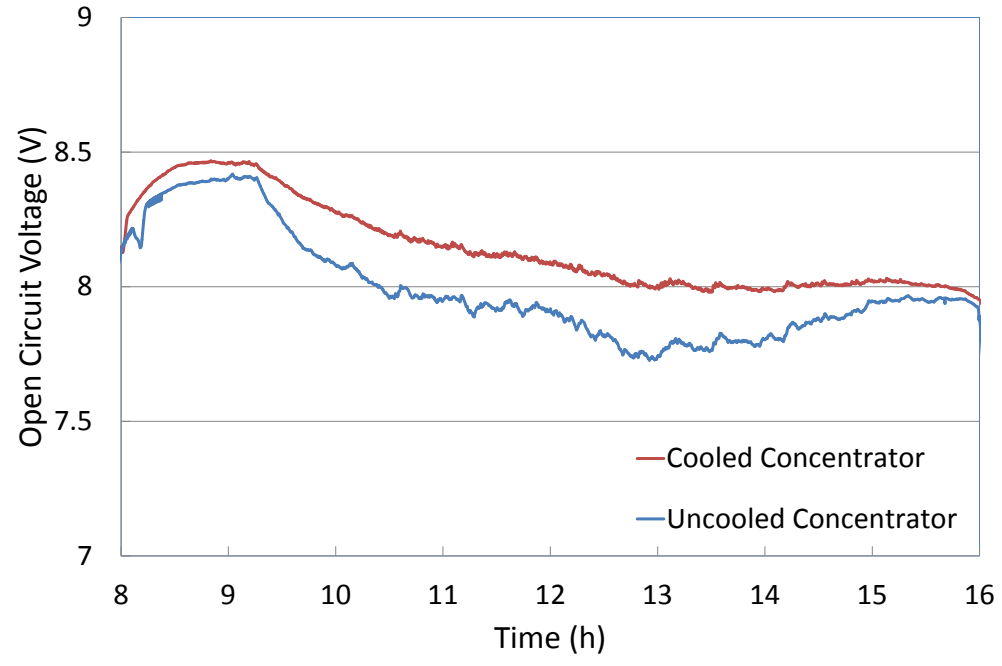

Figure 13: Experimental voltage drop in output 


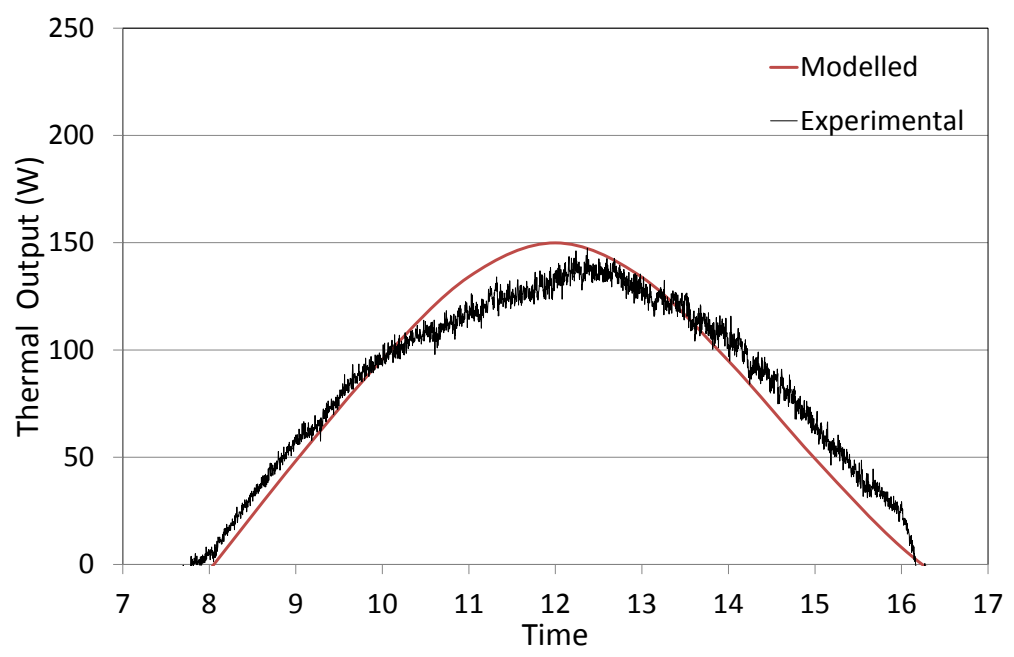

Figure 14: Experimental and modelled thermal output from concentrator 


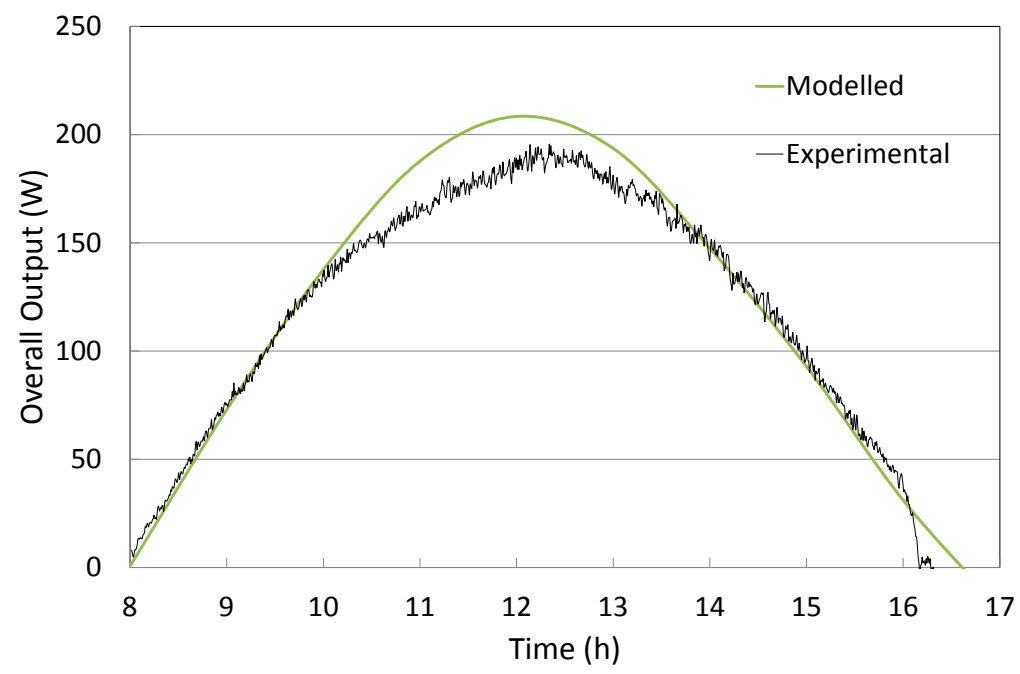

Figure 15: Experimental and modelled total output from concentrator 


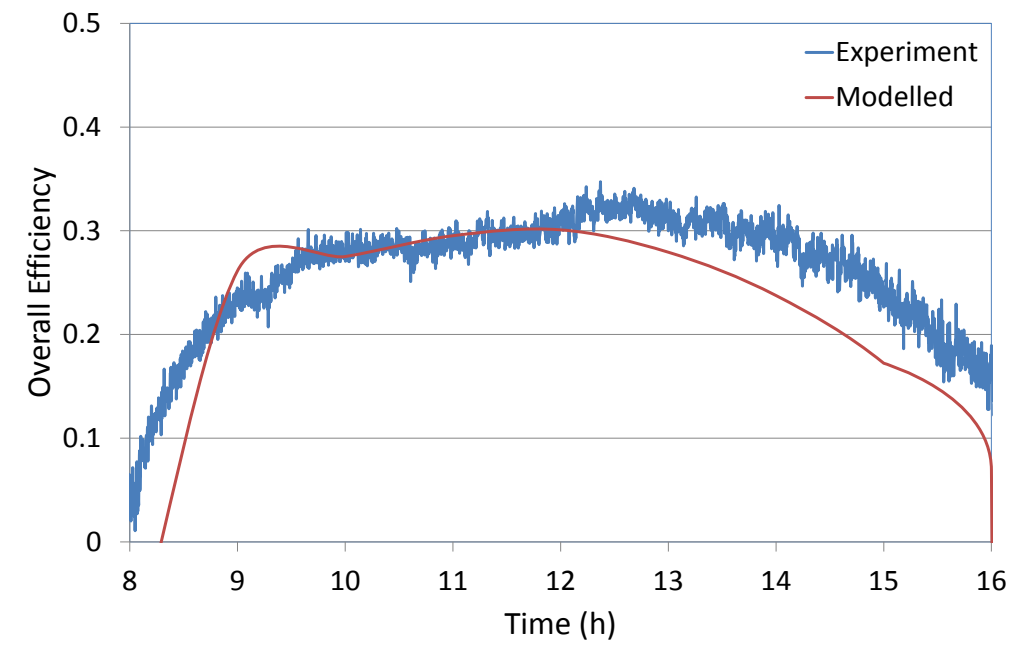

Figure 16: Experimental and modelled efficiency of concentrator 


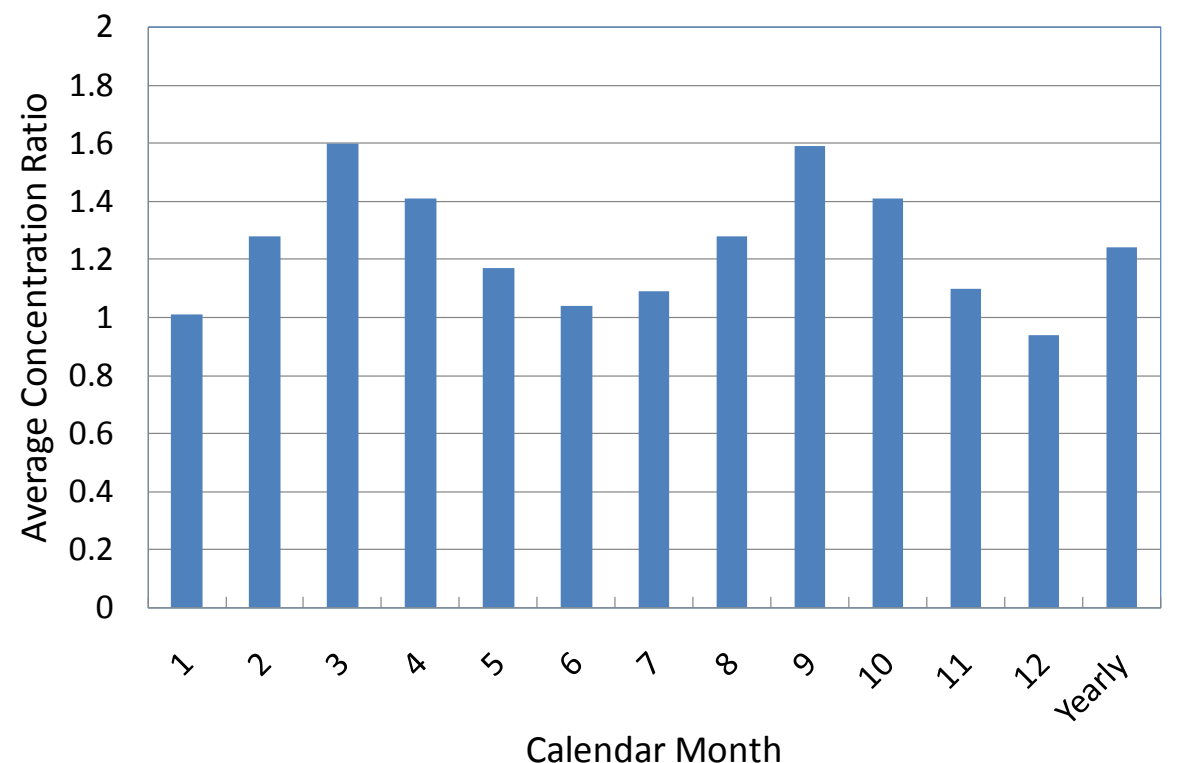

Figure 17: Monthly mean relative concentration ratio 